Joanna Drzazgowska

Uniwersytet Gdański

juanna@poczta.onet.pl

\title{
Construções perifrásticas portuguesas dever + infinitivo e ter de/que + infinitivo - um problema didático
}

\section{Resumo:}

O presente artigo é uma tentativa de apontar quais são os problemas no ensino e na aprendizagem de duas construções perifrásticas de modalidade da língua portuguesa: ter de + infinitivo e dever + infinitivo. A questão em causa está relacionada com a polissemia da perífrase com dever e a suposta sinonímia, em alguns contextos, de ambas as perífrases.

Palavras-chave: modalidade, perífrase verbal, sinonímia, polissemia.

\begin{abstract}
:
Portuguese Verbal Periphrasis with Dever as a Teaching Problem

This article attempts to highlight the problems in teaching and learning of two Portuguese periphrastic modal constructions. The aforementioned problem is related to polysemy of periphrases with dever and supposed synonymy in specific contexts of those periphrases.
\end{abstract}

Keywords: modality, verbal periphrasis, synonymy, polysemy. 
As construções perifrásticas são uma estratégia muito frequente que a língua portuguesa tem ao seu dispor. É um meio muito rico de expressar diferentes valores aspetuais, temporais e modais.

O objetivo do presente artigo consiste na discussão sobre os maiores problemas no âmbito de ensino de duas construções perifrásticas portuguesas de modalidade dever + infinitivo e ter de/que + infinitivo. Não é, portanto, nossa intenção caraterizar de forma exaustiva todos os valores que podem ser expressos pelas perífrases em causa. Cingir-nos-emos aos aspetos cuja análise permita um melhor entendimento das construções mencionadas e que, eventualmente, facilite a sua aprendizagem.

Vejamos, em primeiro lugar, as referências às perífrases e aos valores que estas podem exprimir em algumas gramáticas da língua portuguesa. Ter de/que $e^{1}$, segundo a opinião de diferentes autores, é um meio de expressão de:

1. necessidade (Brandão, 1963: 533; Vázquez Cuesta, Mendes da Luz, 1980: 429; Bechara, 2001: 232; Mateus et al., 2003: 249)

2. obrigação (obrigatoriedade) (Brandão, ibidem; Mattoso Câmara Jr., 1979: 170; Vázquez Cuesta, Mendes da Luz, ibidem; Cunha, Cintra, 1998: 393; Bechara, ibidem; Mateus et al., ibidem)

3. dever (Brandão, ibidem; Bechara, ibidem)

4. firme propósito de realizar um facto (Cunha, Cintra, ibidem)

5. compulsão (Mattoso Câmara Jr., ibidem)

6. probabilidade (em alguns contextos) (Mateus et al., ibidem)

${ }^{1}$ É preciso referirmo-nos à questão do conector na perífrase com o auxiliar ter. Ter é seguido da preposição de nas gramáticas de Mateus et al. (2003), Brandão (1963), Cunha e Cintra (1998), Bechara (2001) e de que no trabalhos de Vázquez Cuesta e Mendes da Luz (1980), Mattoso Câmara Jr. (1979). A única análise que conseguimos encontrar em que o autor diferencia ter de de ter que, devido ao seu valor, é a de Dietrich (1984: 81-82). Segundo o linguista, as construções exprimem obrigação e obrigação incondicionada, respetivamente. No final da nossa análise, seguimos o ponto de vista de Almeida (1980) que considera as duas perífrases como variantes estilísticas. 
O auxiliar dever, por seu turno, serve para exprimir:

1. necessidade (Brandão, ibidem; Bechara, ibidem; Mateus et al., ibidem)

2. obrigação (obrigatoriedade) (Brandão, ibidem; Bechara, ibidem; Mateus et al., ibidem;)

3. dever (Brandão, ibidem; Bechara, ibidem)

4. probabilidade (Mateus et al., ibidem)

Passaremos à analise do problema em causa apresentada nos manuais e gramáticas de português língua estrangeira. Neste caso, ter de + infinitivo pode exprimir:

1. necessidade (Melo Rosa, 1998: 60; Lemos, 2004a: 54; Mata Coimbra, Coimbra, 2009: 92; Coimbra, Mata Coimbra, 2011: 66)

2. obrigação (obrigatoriedade) (Avelar et al., 1993: 37; Avelar et al., 1995: 184; Melo Rosa, 1998: 60; Melo Rosa, 2002: 102; Oliveira, Coelho, 2007a: 40; Oliveira, Coelho, 2007b: 112; Mata Coimbra, Coimbra, 2009; Coimbra, Mata Coimbra, ibidem; Tavares, 2012: 76)

E dever + infinitivo:

1. obrigação (obrigatoriedade) (Avelar et al., 1995: 184; Mata Coimbra, Coimbra, 2001: 85; Coimbra, Mata Coimbra, ibidem; Tavares, op. cit.: 107)

2. probabilidade / possibilidade (Avelar et al., 1993: 97; Avelar et al., 1995: 184; Lemos, 2004a: 82; Lemos, 2004b: 48; Mata Coimbra, Coimbra, 2001: 85; Mata Coimbra, Coimbra, 2009: 92; Coimbra, Mata Coimbra, ibidem; Tavares, ibidem)

3. sugestão relativamente ao futuro (Avelar et al., op. cit.: 34)

4. conselho (Tavares, ibidem)

A primeira observação a fazer é a de que tanto nas gramáticas (seja para estrangeiros, seja para falantes nativos) como nos manuais, as informações relativas ao problema mencionado são escassas. Isto verifica-se tanto nos estudos dos autores portugueses como brasileiros. 
Falta uma análise detalhada das perífrases verbais da modalidade e dos seus valores.

A maioria dos autores enumera a perífrase ter de + infinitivo como meio de expressão de necessidade e obrigação e dever + infinitivo como meio de expressão de obrigação e probabilidade. Em muitos casos, não entram em detalhes nem explicam de que resultam os diferentes valores da perífrase (por exemplo: Lemos (2004a, 2004b); Tavares (2012)).

Noutros casos os linguistas especificam cada valor que a perífrase pode exprimir. Na Gramática Ativa (Coimbra, Mata Coimbra, 2011) e no manual Português XXI (Tavares, 2012) no caso de dever + infinitivo as autoras indicam que relativamente à obrigação expressa pela perífrase em causa, se trata de uma obrigação moral. Quanto a ter del que + infinitivo, as autoras (Coimbra, Mata Coimbra, 2011) sublinham que a construção traduz uma forte necessidade de realizar uma ação.

É interessante que alguns autores enumerem a construção ter de quando analisam as formas que servem para exprimir o futuro. No manual Aprender Português 2 (Oliveira, Coelho, 2007b: 112) e na Gramática Aplicada. Nível Inicial e Elementar (Oliveira, Coelho, 2007a: 40) as autoras apontam que o presente do verbo ter $+d e+$ infinitivo do verbo principal se usa para exprimir obrigação, independente da nossa vontade, de realizar uma ação futura. No manual Vamos lá começar! (Melo Rosa, 2002: 102), por seu turno, podemos ler que o verbo ter + de + infinitivo do verbo principal se utiliza quando queremos indicar uma ação futura de carácter obrigatório. Vale a pena sublinhar neste momento que o verbo ter, que desempenha na construção perifrástica a função de auxiliar, assume não somente os morfemas de pessoa e número do verbo principal, mas também de modo e tempo. Portanto, a obrigação de realizar no futuro pode ser também expressa pelo o verbo ter no futuro, o que não está indicado nos manuais em causa. Além disso, é impossível impor uma obrigação simultânea ao momento da enunciação (ou anterior a ele) visto que é sempre uma obrigação posterior. Portanto, pode ser expressa não apenas devido ao tempo presente ou futuro em que está conjugado o verbo ter, mas também pelo tempo passado (discurso indireto). 
Segundo o nosso parecer, é necessário fazermos particular referência aos manuais brasileiros. Em Passagens (Celli, 2002) as perífrases em causa aparecem em diferentes unidades quatro vezes, mas a autora nunca explica os seus valores, indicando que se emprega dever + infinitivo nas frases tipo deve ser dificil e ter que/de + infinitivo para dar recomendações (ao mesmo tempo a autora sugere o uso de dever no mesmo contexto enunciativo). Igualmente, em outras fontes os autores não dedicam muito espaço ao assunto em causa. Em Aprendendo Português do Brasil (Nazaré de Carvalho Laroca et al., 2003: 19) aparece somente uma referência: Ao analisar o verbo ter no tempo presente, os autores põem exemplos com a perífrase ter quel de + infinitivo para a contrastar com o verbo ter no sentido de possuir mas não especificam os valores que pode exprimir. Em Fala Brasil (Fontão do Patrocínio, Coudry, 2003) não conseguimos encontrar nenhuma informação relativamente aos valores modais expressos pelas construções perifrásticas.

Gostaríamos de sublinhar que o nosso objetivo não é fazer crítica nem das gramáticas da língua portuguesa nem dos manuais para estrangeiros. Queríamos somente apontar que a análise das perífrases ter de + infinitivo e dever + infinitivo não é muito pormenorizada nas fontes referidas e que as construções em causa devido à sua complexidade, que tentaremos seguidamente demonstrar, merecem um estudo mais detalhado.

Tendo em conta o que foi referido, podemos constatar que existem dois problemas principais no ensino e na aprendizagem das perífrases ter de/que + infinitivo e dever + infinitivo: sinonímia das duas construções (quanto à expressão de necessidade e obrigatoriedade) e polissemia da perífrase dever + infinitivo.

O primeiro problema mencionado está relacionado com os próprios conceitos de necessidade e de obrigação. Segundo as gramáticas do português ter de/que + infinitivo e dever + infinitivo exprimem tanto necessidade como obrigatoriedade. No entanto, as gramáticas e os manuais da língua portuguesa para estrangeiros indicam o uso de dever + infinitivo somente quando se trata de exprimir obrigatoriedade. Neste caso, saber distinguir a necessidade da obrigatoriedade 
parece essencial para o emprego correto das duas construções. Visto que conforme o Dicionário da Língua Portuguesa (2009: 1111) necessidade é sinónimo de obrigação e imposição, podemos supor, neste contexto, a sinonímia das construções em causa.

Almeida no seu estudo dedicado às perífrases verbais portuguesas do infinitivo (Almeida, 1980: 134) estabelece uma diferença entre a necessidade que é de ordem natural (conceito mais primitivo da necessidade) e a obrigatoriedade (necessidade de ordem cultural). Portanto, considera a necessidade como um fenómeno mais amplo da natureza e a obrigatoriedade como um fenómeno próprio do homem (o conceito em que entram a consciência, a vontade e a liberdade humana). O linguista, baseando-se em trabalhos de diferentes autores, apresenta na sua análise a seguinte classificação: obrigação material (necessidade física, fisiológica, de natureza material em geral), lógica (deduções do raciocínio, leis do pensamento), moral (leis sociais, costume, decoro, princípios da religião e do indivíduo, dever civil, profissional, religioso, etc.) (Almeida, 1980: 136-138). Na análise de Almeida ambas as perífrases exprimem os três tipos de obrigação (Almeida, 1980). Se seguíssemos o ponto de vista de Almeida, poderíamos considerar ter delque + infinitivo e dever + infinitivo construções sinonímicas, o que neste contexto não contradiz os resultados da nossa análise das gramáticas e dos manuais.

Passemos agora à apresentação do valor de obrigação expresso pelas duas construções. Em primeiro lugar vejamos os exemplos com dever + infinitivo:

1. Acho que, ao menos nisto, devemos conservar alguns princípios (VME: 77$). \approx$ Acho que, ao menos nisto, temos a obrigação de conservar alguns princípios.

2. O chicharro deve ser limpo, escamado e serrilhado, sem cabeça, e se fores um artista podes tirar a espinha pelo meio (VME: 89) $\approx$ É necessário que o chicharro seja limpo, escamado e serrilhado [...]

3. Há uma cidade pequena onde se vende droga barata e onde está frio, deve haver neve (VME: 173). $\approx$ Há uma cidade pequena onde se vende droga barata e onde está frio, obviamente deve haver neve. 
Repare-se que o uso do verbo dever quanto à obrigação moral (1) pode corresponder ao uso da locução ter a obrigação de. No caso da obrigação material (2), como sublinha Almeida (1980: 138), o caráter de obrigação tem um envolvimento passivo e a perífrase equivale à locução ser obrigado a ou ser necessário. Em (3) por se tratar de obrigação lógica, é possível acrescentarmos as expressões adverbiais obviamente, logicamente, ou naturalmente para sublinhar o valor da perífrase. Portanto, verifica-se uma aproximação da probabilidade que se desenvolve a partir deste tipo de obrigação.

Vejam-se os os exemplos com a perífrase ter de + infinitivo:

4. Um bom revolucionário tem de resistir aos apetites (VME: 98).

5. Mas há três anos atrás tivera de proceder a modificações. Alargara o serviço de restaurante, no piso superior, [...] (VME: 25) mat $\approx$ Mas há três anos atrás fora obrigado a proceder a modificações.

6. Era algum, mas você sabe que um jogador de futebol tem de amealhar (VME: 146).

Ter de + infinitivo serve, assim como dever + infinitivo, à expressão de obrigação moral (4), de obrigação material (5) e de obrigação lógica (6). No caso de uma obrigação externa (5), observámos, assim como em (2), um carácter passivo e, neste contexto, a perífrase pode corresponder à locução ser obrigado $a$.

Como tentámos mostrar, existem muitas nuances quanto à expressão de obrigatoriedade que se verificam tanto no caso de dever como de ter de. No entanto, é preciso sublinharmos que nem sempre é fácil observar e diferenciar todos os matizes. Na nossa opinião a questão é muito subjetiva e frequentemente é preciso ter um contexto amplo para decidir sobre o tipo de obrigação. Contudo, queríamos destacar a importância de algumas locuções que correspondem a ambas as perífrases e que podem ser úteis e eficazes no ensino das construções em causa.

Outro problema já mencionado surge no âmbito da análise de dever + infinitivo e está relacionado com a polissemia da perífrase. A construção apresenta uma vasta gama de valores que podem 
expressar: obrigatoriedade/necessidade, possibilidade/probabilidade e ordem. Visto que já analisámos os diferentes tipos de obrigação, passemos neste momento aos outros valores. Com este propósito, vejam-se os seguintes exemplos:

7. De resto não há indicações sobre a casa. Deve ser um lar e não uma casa, deve ter livros a metro, do Círculo de Leitores, uma enciclopédia, deve haver fotografias dele por todo o lado e uma cama grande e larga, isso disseram-me que sim (VME: 128).

8. Uma mala da Louis Vuitton deve custar umas centenas de euros $(\mathrm{FN})^{2}$.

9. De resto, ela era uma boazona, vocês devem gostar (VME: 151).

10. Quando devo comę̧ar? (FN)

11. Deves fazer a tua cama, eu já estou farta de fazê-lo! (FN)

Quando dever + infinitivo serve para exprimir a categoria modal da possibilidade, traduz essencialmente a noção de probabilidade (7). Às vezes, à ideia de probabilidade junta-se o conceito de aproximação, especialmente no caso dos cálculos numéricos (8). A probabilidade apresenta-se às vezes de uma forma mais atenuada, com o caráter de suposição (9). No emprego pouco frequente, que depende do contexto, a perífrase pode exprimir possibilidade propriamente dita (10). No caso da expressão de ordem, trata-se de uma imposição atenuada (11).

No caso de dever, verificam-se os usos deônticos e os usos epistémicos e dentro deles existem muitas interpretações possíveis. É impossível atribuir ao verbo modal a responsabilidade pela distinção de diferentes valores, portanto é necessário procurar outros elementos que possam influir no valor da perífrase. A variedade de fatores que podem influenciar a interpretação de verbos modais polissémicos levou muitos linguistas a estudarem as enunciações com esses verbos e a elaborarem parâmetros de interpretação. Entre as poucas propos-

2 Todos os exemplos inventados por nós foram consultados por falantes nativos (FN) 
tas que existem, queríamos apontar a de Costa Campos (1995) e de Neves (2000) que são a base da nossa análise que se segue. Neves (2000: 129) chama atenção ao infinitivo do verbo principal como um dos fatores da interpretação do valor de dever + infinitivo. $\mathrm{O}$ auxiliar dever combinado com o infinitivo composto exprime somente possibilidade e equivale a é possivel que. A obrigação, por seu turno, tem de se projetar para um momento posterior ao momento da enunciação e não para o momento anterior. Veja-se o exemplo:

12. Deve ter hesitado antes de atender, porque tivera o pressentimento de que a noite estava fria de mais para a época do ano [...] (VME: 46) $\approx$ É possível que ele tenha hesitado antes de atender [...]

No caso da combinação de dever com as formas progressivas a situação é similar por existir também somente uma interpretação do valor da perífrase, a epistémica.

13. A Rosa deve estar a chegar (VME: 84). $\approx$ É possível que a Rosa esteja a chegar.

Não faz sentido obrigar ninguém a realizar uma ação simultânea ao momento da enunciação, logo as interpretações ficam limitadas a é possível que a Rosa esteja a chegar.

No entanto, as formas e tipos de auxiliado não parecem suficientes para se poder decidir se estamos perante uma possibilidade ou obrigação de realizar uma ação. A combinação de dever com o mesmo verbo principal pode dar origem a várias interpretações:

\section{A Teresa deve cantar (FN).}

A frase (14) pode ter tanto uma interpretação epistémica (é possível que a Teresa cante) como deôntica (é necessário que a Teresa cante).

Portanto, alguns linguistas procuram critérios sintáticos que distingam os valores modais, entre eles, Costa Campos (1995) que se baseia na teoria de enunciação de Culioli (Costa Campos, 1995: 95) e tenta encontrar os aspetos formais que permitam diferenciar os valores que a perífrase dever + infinitivo pode exprimir. A autora 
reconhece ser difícil achar uma generalização mas sublinha, acima de tudo, o papel do contexto na interpretação. Constata que o valor da perífrase muda frequentemente devido à presença de um adverbial temporal (Costa Campos, 1995: 95). Vejamos dois exemplos a este propósito:

15. O Paulo deve estar em casa (FN).

16. O Paulo deve estar em casa quando eu voltar do trabalho (FN)

O exemplo (15) é interpretável como epistémico e (16) aceita uma interpretação deôntica pela presença da localização temporal.

De forma breve e não exaustiva, tentámos mostrar que a análise de dois auxiliares de modalidade ter de/que e dever não está isenta de problemas. Ao contrário das gramáticas, por exemplo, da língua inglesa, a questão em causa é um pouco negligenciada. Os autores enumeram vários valores das perífrases, ou seja os seus potenciais significados, mas nunca explicam de que dependem. Nunca aparece, por exemplo, o contexto como um fator determinante do valor da construção perifrástica de modalidade.

No presente artigo esperámos evidenciar a necessidade de desenvolvimento de estudos dedicados às perífrases ter de/que e dever e suscitar o interesse dos investigadores didáticos e autores de manuais pelas construções mencionadas.

\section{Bibliografía}

ALMEIDA, J. de (1980), Introdução ao estudo das perífrases verbais de infinitivo, Ilhpa-Hucitec, Assis-São Paulo.

AVELAR, A. et al. (1993), Lusofonia Curso Básico de Português Língua Estrangeira, Lidel, Lisboa-Porto-Coimbra.

AVELAR, A., MARQUES DIAS, H.B. (1995), Lusofonia Curso Avançado de Português Lingua Estrangeira, Lidel, Lisboa-Porto-Coimbra.

BECHARA, E. (2001), Moderna gramática portuguesa, Editora Lucerna, Rio de Janeiro.

BRANDÃO, C. (1963), Sintaxe clássica portuguesa, Universidade de Minas Gerais, Belo Horizonte. 
CELLI, R. (2002), Passagens - Português do Brasil para Estrangeiros, Pontes, Campinas.

COIMBRA, I., MATA COIMBRA, O. (2011), Gramática Ativa 1, Lidel, Lisboa-Porto-Coimbra.

COSTA CAMPOS, M.H. (1995), "Para uma caracterização do marcador modal dever", Actas do X Encontro da AIL, Lisboa, pp. 93-104, [on-line] http://www.apl.org.pt/docs/actas-10-encontro-apl-1994.pdf 22.11.2013.

CUNHA, C., CINTRA, L. (1998), Nova gramática do português contemporâneo, Edições João Sá da Costa, Lisboa.

Dicionário da Língua Portuguesa, Dicionários Editora, Porto Editora, Porto, 2009.

DIETRICH, W. (1984), “As perífrases verbais de «modalidade» em português", en: Herculano de Carvalho, J.G., Schmidt-Radefeldt, J. (orgs.) Estudos de Linguística Portuguesa, vol. 1, Coimbra Editora, Coimbra, pp. 59-90.

FONTÃO DO PATROCÍNIO, E., COUDRY, P. (2007), Fala Brasil. Português para estrangeiros, Pontes, Campinas.

GONÇALVES, A. (1994), "Aspectos da reestruturação sintáctica em português europeu: as construções com os verbos modais", Actas do IX Encontro da AIL, Lisboa, pp. 235-250. Acessível em: http://www.apl.org. pt/docs/actas-09-encontro-apl-1993.pdf-21.11.2013.

LEMOS, H. (2004a), Praticar Português. Nível Elementar, Lidel, Lisboa-Porto-Coimbra.

LEMOS, H. (2004b), Praticar Português. Nível Intermédio, Lidel, Lisboa-Porto-Coimbra.

MATA COIMBRA, O., COIMBRA, I. (2001), Português sem Fronteiras 2, Lidel, Lisboa-Porto-Coimbra.

MATA COIMBRA, O., COIMBRA, I. (2009), Novo Português sem Fronteiras 1, Lidel, Lisboa-Porto-Coimbra.

MATEUS, M.H.M., BRITO, A.M., DUARTE, I., HUB FARIA, I. (2003), Gramática da Língua Portuguesa, Caminho, Lisboa.

MATTOSO CÂMARA JR., J. (1979), História e estrutura da língua portuguesa, Padrão, Rio de Janeiro.

MELO ROSA, L. (1998), Vamos lá continuar! Explicações e Exercícios de Gramática e Vocabulário (Níveis Intermédio e Avançado), Lidel, Lisboa-Porto-Coimbra.

MELO ROSA, L. (2002), Vamos lá começar! Explicações e Exercícios de Gramática para o Nível Elementar, Lidel, Lisboa-Porto-Coimbra. 
NAZARÉ DE CARVALHO LAROCA, M., BARA, N., CUNHA PEREIRA, S.M. da (2003), Aprendendo Português do Brasil. Um curso para estrangeiros, Pontes, Campinas.

NEVES, M.H. de M. (2000), “A polisemia dos verbos modais. Ou: falando de ambigüidades”, en: Alfa, São Paulo, pp. 115-145. Acessível em: http:// www.seer.fclar.unesp.br/alfa/issue/download/300/48 - 11.11.2013.

OLIVEIRA, C., COELHO, L. (2007a), Gramática Aplicada. Português Língua Estrangeira. Nivel Inicial e Elementar A1, A2 e B1, Texto Editores, Lisboa.

OLIVEIRA, C., COELHO, L. (2007b), Aprender Português 2, Curso Elementar de Língua Portuguesa para Estrangeiros, Nível B1, Texto Editores, Lisboa.

OLIVEIRA, F. (1985), "O futuro em português: alguns aspectos temporais e/ou modais", Actas do I Encontro da AIL, Lisboa, pp. 353-371, [on-line] http://www.apl.org.pt/docs/actas-01-encontro-apl-1985.pdf 11.11.2013.

OLIVEIRA, F. (1990), "Modais e Condicionais", Actas do V Encontro da AIL, Lisboa, pp. 145-161.

OLIVEIRA, F. (1993), "Questões sobre Modalidade em Português", Cadernos de Semântica, 15.

TAVARES,A.(2012), Português XXI.NívelA1, Lidel,Lisboa-Porto-Coimbra. VÁZQUEZ CUESTA, P., MENDES DA LUZ, M.A. (1980), Gramática da língua portuguesa, Edições 70, Lisboa.

VIEGAS, F.J. (2009), Morte no estádio, Bertrand Editora, Ltd., Lisboa (abreviação utilizada: VME). 